\title{
Desigualdades sociais na velhice e as potencialidades da prática intersetorial em saúde: algumas considerações gerontológicas
}

\author{
Roberth Steven Gutiérrez Murillo'
}

\begin{abstract}
Resumo
O trabalho buscou analisar o discurso da prática intersetorial como ferramenta de combate às desigualdades sociais em saúde, nomeadamente, àquelas vinculadas ao processo do envelhecimento humano. Trata-se de um ensaio crítico, de cunho analítico-descritivo, com abordagem qualitativa, valendo-se da literatura que aborda a questão da desigualdade social em idosos e as práticas sanitárias intersetoriais no âmbito do Sistema Único de Saúde. As informações trazidas no estudo pretendem realizar aportes à ciência gerontológica, na medida em que retomam a questão da integralidade dos cuidados oferecidos ao idoso em contextos de desamparo social.
\end{abstract}

\author{
Palavras-chave \\ Intersetorialidade; Saúde do Idoso; Determinantes Sociais em Saúde; Envelhecimento.
}

Social inequalities in old age and the potential of intersectoral health practice: some gerontological considerations

\begin{abstract}
This paper analyzed the discourse of intersectoral practice as a tool to combat social inequalities in health, particularly those linked to the process of human aging. It is a critical essay, of analytical-descriptive nature, with qualitative approach, using the literature that addresses the issue of social inequality in the elderly and intersectoral health practices in the scope of the Unified Health System. The information brought in the study intends to make contributions to gerontological science, as they take up the question of the integrality of the care offered to older adults in contexts of social helplessness.
\end{abstract}

Keywords

Intersectionality; Health of the Elderly; Social Determinants in Health; Aging.

Artigo recebido: novembro de 2020

Artigo aceito: dezembro de 2020 


\section{Introdução}

Como resultado dos múltiplos avanços científicos e tecnológicos, em complemento das reivindicações e direitos sociais outorgados ao ser humano, nas sociedades contemporâneas têm avistado um considerável aumento da expectativa de vida na estrutura sociodemográfica. Em países desenvolvidos e naqueles em vias para o desenvolvimento, tal aumento da expectativa de vida, tem sido mais evidenciado (ANTUNES, 2018).

Se, por um lado, maior expectativa de vida representaria mais anos a serem vividos (idade cronológica), por outro, nem sempre esses anos vêm acompanhados de ótimas condições para o desenvolvimento humano (idade subjetiva), cenário tal que contempla os âmbitos econômico, social, sanitário e ambiental. De fato, Medeiros (2020, p.370) reitera que, o aumento da expectativa de vida "tem sido acompanhado, contraditoriamente, pela grande desigualdade histórica e social na distribuição de renda e serviços que caracteriza nosso país em diversas regiões".

Desse modo, a discussão sobre a qualidade de vida (QV) vê-se entrelaçada à análise da expectativa de vida e à forma na qual as pessoas percebem sua idade subjetiva. A QV, per se, configura tópico melindroso e polissêmico nos estudos sociossanitários, especialmente naqueles propostos através das lentes da Saúde Coletiva, que se preocupam por entender e explanar as condições de vida das sociedades e as relações (intrínsecas e/ou extrínsecas) entre o meio e a capacidade de resposta aos fatores estressores (CACHIONI et al., 2017).

Citando, por exemplo, Minayo; Hartz e Buss (2000, p. 8), consideram QV como uma "noção eminentemente humana, que tem sido aproximada ao grau de satisfação encontrado na vida familiar, amorosa, social e ambiental e à própria estética existencial". Portanto, nota-se que a compreensão do grau de QV leva em consideração a história de vida do indivíduo, ponderando situações ora classificadas como 'positivas' e/ou 'negativas', a partir do juízo subjetivo dessas vivências. 
Ainda, no debate da QV na velhice, cumpre reter que as desigualdades sociais em saúde (DSS) constituem sério entrave para o real gozo do direito à saúde e plenitude da atenção integral às populações. Conceitualmente, DSS “são consequências das condições socioeconômicas das pessoas, afetando o contexto em que nascem, crescem, vivem, trabalham e envelhecem" (PÉREZ-HERNÁNDEZ et al., 2017, p. 146). Portanto, estudar as DSS na velhice se torna relevante, na medida em que se entende que "o acúmulo de diferentes problemas crônicos de saúde leva a um crescimento quase exponencial nos gastos em serviços de saúde" (ANTUNES et al., 2018, p. 2). A esse respeito, Noronha e Andrade (2005, p. 411) afirmam que:

Na América Latina, os estudos existentes avaliam a presença de desigualdades considerando todos os grupos etários e indicam que, quanto melhores as condições sociais dos indivíduos ou das localidades, melhor é o estado de saúde e o acesso aos serviços. Como os idosos apresentam um estado de saúde mais vulnerável, e como a fração da renda gasta com saúde é maior para esse grupo populacional, a investigação acerca da presença dessas desigualdades é um subsídio importante para a definição de políticas públicas e sociais na região.

Nessa mesma lógica, cumpre retomar o exposto por Lima-Costa et al., (2003), ao postularem três possíveis hipóteses para explicar a influência das DSS na velhice no contexto brasileiro. Em primeiro lugar, tem-se que "as diferenças de renda diminuem após a aposentadoria e isso, como consequência, reduz diferenças dos indicadores sociais e de saúde". Uma segunda hipótese sustenta que "as políticas sociais com o objetivo de reduzir as desigualdades entre os idosos minimizam diferenças de acesso aos serviços médicos de qualidade, com reflexos na situação de saúde" e, por último, a terceira hipótese defende o "viés de sobrevivência e/ou viés em virtude de não-participação" dos idosos considerados na maioria das pesquisas desenvolvidas no país (LIMA-COSTA et al., 2003, p. 746). Para as autoras, é justo dizer que 
muitas são as formas nas quais as DSS afetam à saúde do idoso, sendo assim, estudos que visem a devassar referido campo, necessitam ser respaldados por metodologias que permitam entender/respeitar a heterogeneidade desse segmento populacional.

Outros autores enfatizam a obrigação estatal de zelar pelo bem-estar dos cidadãos envelhecidos, justamente pela observância dos princípios bioéticos em decorrência do fazer sociossanitário. Citando caso análogo, Schumacher; Puttini e Nojimoto (2013) evocam para o compromisso com o cuidado e a orientação de uma política de saúde integral que permita atender as demandas complexas do envelhecimento, implicando, por sua vez, nas múltiplas maneiras de viver do ser humano. Complementarmente, Pereira (2015, p. 124) afirma que os direitos sociais atualmente reconhecidos à pessoa idosa "não surgiram por acaso e nem foram outorgados pelos governantes", pois, tais direitos configuram o produto final de muitas lutas sociais de outrora, devendo o Estado manter seu comprometimento social, "não apenas a coibir infrações praticadas contra os idosos, mas a elevar a QV desse segmento populacional por meio de políticas públicas efetivas". Nessa sequência, faz sentido apontar que "a intersetorialidade pode trazer ganhos para a população, para a organização logística das ações definidas, bem como para a organização das políticas públicas centradas em determinados territórios" (NASCIMENTO, 2010, p. 96).

É, nesse cenário marcado pelas DSS, que cumpre falar na prática da intersetorialidade levantando debate para a compreensão das possibilidades que dito método oferece no combate às DSS na velhice. Assim, a Prática Intersetorial em Saúde (PIS) surge como mecanismo democratizador e promotor dos princípios doutrinários do Sistema Único de Saúde (SUS), na tentativa de integrar, universalizar e fazer equitativa toda assistência proporcionada ao usuário, em qualquer fase da vida humana e, por isso, fomenta o desenvolvimento cidadão dos usuários por meio de estratégias de mobilização de massas com interesses co- 
letivos afins. Em tempo, vale alentar que o empoderamento cidadão constitui ferramenta essencial para os processos de democratização sanitária e fortalecimento das redes de atenção social e sanitária.

Intersetorialidade pode ser definida como "a articulação de saberes e experiências no planejamento, realização e avaliação de ações para alcançar efeito sinérgico em situações complexas visando ao desenvolvimento social, superando a exclusão social" (JUNQUEIRA, 2004, p. 131). Nessa acepção, a intersetorialidade "constitui uma concepção que deve ser informar uma nova maneira para planejar, executar e controlar a prestação de serviços. Isso significa alterar toda forma de articulação dos diversos segmentos" (JUNQUEIRA, 2004, p. 131).

Em particular, o destaque para a intersetorialidade em saúde se evidencia na efetivação dos princípios organizacionais do SUS, quais sejam: descentralização político-administrativa; regionalização e hierarquização da rede de serviços de saúde; integração em nível executivo das ações em saúde, meio ambiente e saneamento básico; conjugação dos recursos na prestação de serviços de assistência à saúde da população; capacidade de resolução de todos os níveis de assistência e organização dos serviços públicos de modo a evitar duplicidade de meios para fins idênticos (MATTA, 2007). Numa visão ampliada, a PIS propõe organizar a atenção brindada ao idoso na forma de rede assistencial, tornando-se uma prática dinâmica, uma vez que "a integração entre diferentes áreas e a abordagem de problemas de forma criativa demanda mudanças individuais, institucionais e ações intersetoriais" (MOTTA; AGUIAR, 2007, p. 367).

Considerando o cenário exposto, o trabalho objetivou analisar o discurso da PIS como ferramenta para combater as desigualdades sociais em saúde, nomeadamente, aquelas vinculadas ao processo do envelhecimento humano. Assim, a análise proposta nesse trabaIho responde à necessidade de alimentar a discussão contemporânea das desigualdades sociais na velhice, tentando, por vez, dimensionar questões vinculadas à atenção integral à saúde do idoso. 
Metodologicamente, foi estruturado um ensaio crítico de cunho analítico-descritivo, que adotou a abordagem qualitativa para a interpretação dos dados, por meio de revisão da literatura, considerando que dito método "permite definir bem o problema e obter uma ideia precisa sobre o estado atual dos conhecimentos sobre um dado tema, as suas lacunas e a contribuição da investigação para o desenvolvimento do conhecimento" (BENTO, 2012, p. 1). A coleta de dados foi realizada por meio de consulta on-line nas bases científicas virtuais Scientific Electronic Library Online - SciELO e Google Acadêmico. Na extração dos dados foram empregados os descritores 'intersetorialidade'; 'sistema único de saúde'; 'envelhecimento' e 'idoso'. Foram incluídos neste estudo artigos completos (full text), de livre acesso, escritos em língua portuguesa, respeitando um período de publicação não inferior ao ano de 2010 e não superior ao ano de 2019, não havendo sido aplicado critério de exclusão em relação aos participantes, nem à metodologia adotada pelos autores, contudo, os trabalhos deveriam ter sido desenvolvidos em quaisquer níveis de atenção à saúde do idoso no SUS.

\section{Resultados}

Na Tabela 1, apresenta-se a descrição dos artigos científicos selecionados para a composição do corpus do trabalho, em relação ao autor, ano de publicação, título do trabalho e desenho adotado no estudo. Após a aplicação dos critérios de inclusão, foram identificados apenas dez (10) trabalhos que discutiam a questão da intersetorialidade na velhice, no contexto do SUS. Notou-se predominância do tipo de estudo exploratório ( $n=4 ; 40 \%)$ e análise documental $(n=3 ; 30 \%)$ e período de publicação entre 2014 e 2016 ( $n=5 ; 50)$. 
Tabela 1. Caracterização dos trabalhos selecionados neste estudo, 2020.

\begin{tabular}{|c|c|c|c|}
\hline AUTOR(ANO) & ID & TÍTULO & DESENHO \\
\hline Mangueira (2016) & A & $\begin{array}{l}\text { Intersetorialidade em saúde: } \\
\text { algumas considerações. }\end{array}$ & Teórico-conceitual \\
\hline $\begin{array}{l}\text { Veiga e Bronzo } \\
\text { (2014). }\end{array}$ & B & $\begin{array}{l}\text { Estratégias intersetoriais de } \\
\text { gestão municipal se serviços de } \\
\text { proteção social: a experiência de } \\
\text { Belo Horizonte. }\end{array}$ & $\begin{array}{l}\text { Exploratório- } \\
\text { descritivo }\end{array}$ \\
\hline $\begin{array}{l}\text { Motta; Aguiar e } \\
\text { Caldas (2011). }\end{array}$ & C & $\begin{array}{l}\text { Estratégia Saúde da Família e a } \\
\text { atenção ao idoso: experiências } \\
\text { em três municípios brasileiros. }\end{array}$ & Exploratório \\
\hline $\begin{array}{l}\text { Freitas e Teófilo } \\
(2010) .\end{array}$ & D & $\begin{array}{l}\text { Avaliação construtivista, sob } \\
\text { uma abordagem integradora } \\
\text { e intersetorial, das ações do } \\
\text { Projeto Disque Idoso em Sobral } \\
\text { (CE, Brasil). }\end{array}$ & $\begin{array}{l}\text { Exploratório- } \\
\text { descritivo }\end{array}$ \\
\hline $\begin{array}{l}\text { Souza e Machado } \\
(2018) \text {. }\end{array}$ & $E$ & $\begin{array}{l}\text { Governança, intersetorialidade } \\
\text { e participação social na política } \\
\text { pública: o Conselho Nacional } \\
\text { dos Direitos da Pessoa Idosa. }\end{array}$ & Análise documental \\
\hline $\begin{array}{l}\text { Oliveira; Ramos; } \\
\text { Panhoca e Alves } \\
\text { (2014). }\end{array}$ & $F$ & $\begin{array}{l}\text { A intersetorialidade nas políticas } \\
\text { públicas para o envelhecimento } \\
\text { no Brasil. }\end{array}$ & Análise documental \\
\hline $\begin{array}{l}\text { Oliveira; Mattioli; } \\
\text { Barcelos; Horta e } \\
\text { Lacerda (2017). }\end{array}$ & G & $\begin{array}{l}\text { Promoção da saúde e } \\
\text { intersetorialidade na rede de } \\
\text { atenção ao idoso. }\end{array}$ & $\begin{array}{l}\text { Exploratório- } \\
\text { descritivo }\end{array}$ \\
\hline $\begin{array}{l}\text { Cavalcante; } \\
\text { Carvalho e } \\
\text { Medeiros (2012). }\end{array}$ & $\mathrm{H}$ & $\begin{array}{l}\text { Intersetorialidade, políticas } \\
\text { sociais e velhice no Brasil: entre } \\
\text { a falácia e a efetivação do direito } \\
\text { social. }\end{array}$ & Análise documental \\
\hline $\begin{array}{l}\text { Rocha e Romagnoli } \\
\text { (2015). }\end{array}$ & $\mathrm{J}$ & $\begin{array}{l}\text { Cuidado com a velhice: } \\
\text { interdisciplinaridade e } \\
\text { intersetorialidade. }\end{array}$ & Ensaio \\
\hline Faustino (2016). & K & $\begin{array}{l}\text { Intersetorialidade: tendência } \\
\text { contemporânea na organização } \\
\text { de políticas públicas - a } \\
\text { experiência do Programa Maior } \\
\text { Cuidado. }\end{array}$ & Revisão de literatura \\
\hline
\end{tabular}

Fonte: Banco de dados da pesquisa (2020). 
ídas nos trabalhos considerados neste estudo. Observou-se que a intersetorialidade em saúde mostrou importantes variações conceituais entre os trabalhos, justificados principalmente pelo tipo de objetivo traçado e ambiente onde as pesquisas foram desenvolvidas. Alguns estudos (A, E e F) referenciaram a prática intersetorial como ferramenta de gestão em saúde, entrelaçando-a com outros princípios organizacionais como: regionalização e hierarquização, descentralização e comando único e participação popular.

Quadro 01. Síntese conceitual da "intersetorialidade em saúde do idoso", segundo artigos selecionados neste estudo, 2020.

\begin{tabular}{|c|c|c|}
\hline ID & OBJETIVO & PRINCIPAIS ACHADOS \\
\hline A & $\begin{array}{l}\text { Analisar sob a ótica da } \\
\text { literatura, a aplicabilidade } \\
\text { da intersetorialidade como } \\
\text { forma de articulação na } \\
\text { Atenção Primária mediante } \\
\text { uma Revisão Integrativa de } \\
\text { Literatura. }\end{array}$ & $\begin{array}{l}\text { A intersetorialidade é uma estratégia política } \\
\text { complexa, cujo resultado na gestão de uma cidade } \\
\text { é a superação da fragmentação das políticas nas } \\
\text { várias áreas onde são executadas. Tem como } \\
\text { desafio articular diferentes setores na resolução } \\
\text { de problemas no cotidiano da gestão e torna-se } \\
\text { estratégia para a garantia do direito à saúde. }\end{array}$ \\
\hline B & $\begin{array}{l}\text { Analisar a experiência } \\
\text { do Programa BH } \\
\text { Cidadania, desenvolvido } \\
\text { pela Prefeitura de Belo } \\
\text { Horizonte desde } 2002 .\end{array}$ & $\begin{array}{l}\text { Os arranjos intersetoriais não substituem } \\
\text { as especializações disciplinares e técnico- } \\
\text { operativas de cada política, mas pretendem } \\
\text { perpassar os setores, instaurando alterações na } \\
\text { forma de produção dos serviços, na percepção } \\
\text { dos problemas e sobre como enfrentá- } \\
\text { los, mudanças no uso dos recursos e de } \\
\text { implementação dos serviços. }\end{array}$ \\
\hline C & $\begin{array}{l}\text { Analisar a atenção ao idoso } \\
\text { no trabalho da Estratégia } \\
\text { Saúde da Família em três } \\
\text { municípios do Estado do } \\
\text { Rio de Janeiro. }\end{array}$ & $\begin{array}{l}\text { A construção de uma rede de atenção à saúde } \\
\text { do idoso é o maior desafio, por sua natureza } \\
\text { complexa. Demanda a oferta de diversos tipos } \\
\text { de serviços, que necessitam de fontes de } \\
\text { financiamento, às vezes distintos, que devem ser } \\
\text { estruturadas de forma regionalizada, integrada, } \\
\text { com o objetivo de garantir a longitudinalidade } \\
\text { da atenção. A falta de serviços com objetivos } \\
\text { distintos como reabilitação, cuidado de } \\
\text { enfermagem, cuidado paliativo, cuidado } \\
\text { para portadores de incapacidade física e/ou } \\
\text { mental fragmenta e dificulta uma assistência } \\
\text { longitudinal e cuidadora. }\end{array}$ \\
\hline
\end{tabular}




\begin{tabular}{|c|c|c|}
\hline D & $\begin{array}{l}\text { Guiar pelo Método de } \\
\text { Avaliação Construtivista de } \\
\text { Furtado, o qual tem como } \\
\text { base proporcionar aos } \\
\text { avaliadores subsídios para } \\
\text { realização de avaliações } \\
\text { pluralistas e participativas. }\end{array}$ & $\begin{array}{l}\text { O Disque Idoso em Sobral funciona como uma } \\
\text { rede de apoio ao idoso, que na ótica da relação } \\
\text { violência-adoecimento requer uma atenção } \\
\text { especial dos serviços de saúde. A rede social } \\
\text { de apoio está pautada na necessidade de se } \\
\text { ampliar às ações voltadas para a proteção } \\
\text { do idoso através da articulação de diferentes } \\
\text { instâncias e serviços que têm um fim em comum. } \\
\text { A interlocução entre órgãos e instituições torna-se } \\
\text { essencial para a garantia dos direitos dos idosos. }\end{array}$ \\
\hline $\mathrm{E}$ & $\begin{array}{l}\text { Analisar o conselho } \\
\text { nacional dos direitos da } \\
\text { pessoa idosa (CNDI) a } \\
\text { partir da descrição da } \\
\text { configuração institucional } \\
\text { e caracterização da sua } \\
\text { atuação na proposição } \\
\text { de estratégias de } \\
\text { implementação e } \\
\text { acompanhamento das } \\
\text { principais políticas para os } \\
\text { idosos. }\end{array}$ & $\begin{array}{l}\text { O CNDI representa uma estrutura inovadora } \\
\text { de governança, que procura promover a } \\
\text { articulação intersetorial entre órgãos públicos } \\
\text { e ampliar a participação da sociedade civil nas } \\
\text { políticas para os idosos. No que se refere à } \\
\text { agenda política, destaque-se o papel do CNDI } \\
\text { na defesa da implementação da legislação de } \\
\text { proteção dos idosos a partir de estratégias junto } \\
\text { as diferentes esferas e Poderes (Executivo, } \\
\text { Judiciário e Legislativo). }\end{array}$ \\
\hline$F$ & $\begin{array}{l}\text { Mostrar a necessidade de } \\
\text { políticas intersetoriais no } \\
\text { que concerne às políticas } \\
\text { para a população idosa no } \\
\text { Brasil. }\end{array}$ & $\begin{array}{l}\text { Percebem-se avanços no Brasil nas políticas } \\
\text { para a pessoa idosa, como é o caso das políticas } \\
\text { de saúde, dos direitos sociais e da assistência. } \\
\text { No entanto, ainda é necessária uma melhora na } \\
\text { efetivação dessas políticas. Diferentes setores } \\
\text { governamentais executam as suas políticas; no } \\
\text { entanto, percebe-se que esses setores não se } \\
\text { conversam para melhorar ações que garantam } \\
\text { políticas de qualidade para essa população. } \\
\text { Sendo assim, compreende-se que políticas } \\
\text { intersetoriais podem contribuir para a qualidade } \\
\text { de vida da população idosa e, por isso, torna- } \\
\text { se necessário repensar a maneira de como são } \\
\text { implementadas as políticas públicas voltadas } \\
\text { para o envelhecimento. }\end{array}$ \\
\hline
\end{tabular}




\begin{tabular}{|c|c|c|}
\hline $\mathbf{G}$ & $\begin{array}{l}\text { Analisar a relação entre } \\
\text { promoção da saúde na } \\
\text { rede de cuidados e a } \\
\text { perspectiva intersetorial na } \\
\text { atenção ao idoso. }\end{array}$ & $\begin{array}{l}\text { No que tange à promoção da saúde, as ações } \\
\text { destinadas ao idoso são pontuais e isoladas, } \\
\text { advindas de uma redução conceitual desse } \\
\text { termo. Os grandes desafios que devem } \\
\text { ser enfrentados para que se avance nesse } \\
\text { processo é o entendimento do conceito de } \\
\text { promoção da saúde e a articulação da teoria } \\
\text { com a prática. Partindo-se do pressuposto de } \\
\text { que a intersetorialidade é um dos princípios } \\
\text { da promoção da saúde e que esses conceitos } \\
\text { são indissociáveis, é imprescindível a esses } \\
\text { municípios melhor articulação e implementação } \\
\text { das políticas integrais e intersetoriais, não } \\
\text { apenas como ações fragmentadas, mas como } \\
\text { melhorias que devem ser incorporadas à prática } \\
\text { cotidiana na atenção ao idoso. }\end{array}$ \\
\hline $\mathrm{H}$ & $\begin{array}{l}\text { Levantar subsídios acerca } \\
\text { da importância das } \\
\text { ações intersetoriais nos } \\
\text { programas de proteção } \\
\text { social à velhice, face à } \\
\text { natureza que o processo } \\
\text { de envelhecimento impõe, } \\
\text { principalmente, no que } \\
\text { se refere à assistência à } \\
\text { saúde. }\end{array}$ & $\begin{array}{l}\text { Na produção do cuidado em saúde junto à } \\
\text { pessoa idosa (prevenção, promoção, cura } \\
\text { e reabilitação), há que se atentar para as } \\
\text { peculiaridades que o envelhecimento humano } \\
\text { demanda, o que envolve nuances de ordem } \\
\text { biopsicossocial que não serão enfrentadas a } \\
\text { partir de um único setor. A intersetorialidade } \\
\text { pressupõe mudanças endógenas das políticas } \\
\text { de proteção social e exógenas, dessas entre } \\
\text { si. Impõe, ainda, a compreensão por parte dos } \\
\text { gestores de que, em função da complexidade } \\
\text { das expressões da questão social, um setor } \\
\text { apenas não consegue dar conta das demandas } \\
\text { multifacetadas que surgem. }\end{array}$ \\
\hline$J$ & $\begin{array}{l}\text { Responder, mesmo } \\
\text { que provisoriamente, a } \\
\text { seguinte questão: como } \\
\text { se dá a aplicação da } \\
\text { intersetorialidade no } \\
\text { Projeto Cuidador de Idosos } \\
\text { e quais são os efeitos } \\
\text { das ações intersetoriais } \\
\text { no desenvolvimento da } \\
\text { melhoria da qualidade } \\
\text { de vida dos idosos e na } \\
\text { capacidade de proteção } \\
\text { das famílias e do Estado } \\
\text { a esse segmento da } \\
\text { sociedade? }\end{array}$ & $\begin{array}{l}\text { A intersetorialidade permite uma resposta mais } \\
\text { integral e adequada às demandas atuais, evitando } \\
\text { sobreposição de ações, possibilitando novos } \\
\text { arranjos organizacionais, permitindo maior } \\
\text { eficiência e resultados mais significativos quanto } \\
\text { ao impacto e sustentabilidade das políticas. a } \\
\text { intersetorialidade é vista como uma boa estratégia } \\
\text { de gestão, que evita sobreposição de ações, } \\
\text { produz uma capacidade de ser mais responsiva e } \\
\text { qualificada no atendimento ao usuário, concentra } \\
\text { esforços financeiros e humanos, permitindo um } \\
\text { resultado mais integral à ação pública diante de } \\
\text { problemas sociais cada vez mais complexos. } \\
\text { No entanto a intersetorialidade, assim como a } \\
\text { interdisciplinaridade, é um processo complexo, } \\
\text { que envolve o enfrentamento de contradições, } \\
\text { restrições e resistências. }\end{array}$ \\
\hline
\end{tabular}




\begin{tabular}{|l|l|l|}
\hline K & $\begin{array}{l}\text { A Intersetorialidade tem sido uma defesa retórica } \\
\text { reiteradamente afirmada em textos e debates } \\
\text { sobre as políticas sociais, principalmente quando } \\
\text { o conteúdo da política está relacionado ao } \\
\text { combate à fome e à exclusão. A intensificação das } \\
\text { expressões da Questão Social demanda soluções } \\
\text { integradas e não setorializadas, já que a realidade } \\
\text { social não se manifesta de maneira dicotômica. } \\
\text { implementação de uma } \\
\text { experiência municipal de } \\
\text { gestão intersetorial. }\end{array}$ & $\begin{array}{l}\text { Para que a Intersetorialidade ganhe força, é } \\
\text { necessário que o diálogo entre os setores seja } \\
\text { incentivado mediante políticas que apresentem } \\
\text { desenhos institucionais intersetoriais. As } \\
\text { construções de políticas públicas e sociais com } \\
\text { essa concepção ainda estão em desenvolvimento, } \\
\text { mas é só recentemente que o desafio da } \\
\text { Intersetorialidade vem sendo tratado de forma } \\
\text { mais concreta, ocupando lugar de destaque na } \\
\text { agenda de debate da área social do Governo } \\
\text { Federal e sendo defendida por diversos analistas } \\
\text { de política pública. }\end{array}$ \\
\hline
\end{tabular}

Fonte: Banco de dados da pesquisa (2020).

\section{Discussão}

Em 2015, por meio da Assembleia Geral das Nações Unidas (ONU), foram estabelecidas metas globais a serem incorporadas nas agendas políticas dos países signatários, dentre os quais se encontra o Brasil. Em consequência, os países elaboraram um documento coletivo intitulado Transforming our world: the 2030 Agenda for Sustainable Development (ONU, 2015).

Referido documento foi composto por 17 objetivos específicos, também chamados de objetivos para o desenvolvimento sustentável (ODS), os quais visam, principalmente, a "concretizar os direitos humanos, alcançar a igualdade de gênero e o empoderamento das muIheres e meninas" (ONU, 2015). Dessa forma, os ODS foram pensados para "acabar com a pobreza e a fome, em todas as suas formas e dimensões, e garantir que todos os seres humanos possam realizar o seu potencial em dignidade e igualdade, em um ambiente saudável" (ONU, 2015). Igualmente, os ODS configuram instrumento internacional para o combate às DSS, tais sejam os casos: 
ODS 1 - acabar com a pobreza em todas suas formas, em todos os lugares; ODS 3 - assegurar uma vida sustentável e promover o bem-estar para todos, em todas as idades; ODS 10 - reduzir a desigualdade dentro dos países e entre eles; ODS 16 - promover sociedades pacíficas e inclusivas para o desenvolvimento sustentável, proporcionar o acesso à justiça para todos e construir instituições eficazes, responsáveis e inclusivas em todos os níveis (ONU, 2015).

Na observância dos ODS supramencionados, vale reafirmar a importância da PIS como ferramenta para o combate às DSS na velhice, pois a "intersetorialidade realiza o atendimento a partir do indivíduo enquanto sujeito de direitos, priorizando suas ações como proposta arrojada da gestão pública, oportunizando parcerias entre os setores" (MANCUEIRA, 2016, p. 3). Complementarmente, Veiga e Bronzo (2014, p. 616) afirmam que "um ou dois programas setoriais dificilmente podem reverter quadros de violação de direitos, abusos e maus tratos". Para os autores, fica claro que "vulnerabilidade e exclusão podem produzir situações familiares em que a família se torna um dos agentes de exposição de seus membros a situações de risco e de violação de direitos". Esse apontamento não figura de forma diferente, se comparado às diversas DSS na velhice narradas pela literatura gerontológica (SCHUMACHER et al., 2013; PEREIRA, 2015).

Por outro lado, para apregoar-se atenção integral à saúde do idoso é necessário, em primeiro momento, repensar as formas de produzir atos em saúde. Assim, toda ação realizada no âmbito da prestação de serviços profissionais, deve ser qualificada e orientada sobre princípios bioéticos, que orientam as formas do cuidado à saúde humana, em termos da autonomia - respeitando a vontade do idoso; não maleficência - buscando não gerar nenhum dado ao idoso, justiça - que diz respeito à apropriação da equidade e igualdade no provimento de cuidados e; não menos importante beneficência - adoptando a concepção biopsicossocial da saúde. Logo, a assistência institucional (em 
quaisquer que sejam os dispositivos sociossanitários ativados), deve agir de acordo a normativa jurídico-sanitária vigente. No caso próprio do Brasil, pode ser observado que a PIS configura diretriz técnica não só para os serviços de saúde, havendo igual grau de incumbência nas esferas: social, econômico, cultural e ambiental.

O trabalho de Motta; Aguiar e Caldas (2011) analisou a atenção ao idoso desempenhada por profissionais da Estratégia Saúde da Família em três municípios do Rio de Janeiro. Os autores reconhecem a complexidade das redes de atenção à saúde do idoso, principalmente ao indicarem como principal desafio a integração de outros setores, além da saúde, por exemplo, educação e assistência social. Igualmente, destacaram a "desorganização da rede, a falta de estruturas de apoio e a falta de integração dos serviços existentes" como empecilhos para a concretização da atenção integral ao idoso (MOTTA; AGUIAR; CALDAS, 2011, p. 785).

Do exposto, surgem duas questões que merecem ser discutidas. A princípio, é importante reter que a integralidade em saúde "enseja a flexibilização da divisão técnica do trabalho" (MOTTA; ACUIAR, 2007, p. 366). À vista disso, integralidade em saúde nada mais é do que o ato de qualificar o processo de trabalho dos profissionais de saúde e do sistema de saúde como tal, com vistas a providenciar uma atenção que vá de acordo com a mais alta qualidade assistencial, na observância das premências particulares do usuário. Isso envolve, para além dos elementos tangíveis, a própria qualificação e aprimoramento dos recursos humanos em temáticas vinculadas ao processo de envelhecimento.

Como segunda questão, têm-se a articulação entre redes de cuidado para idosos (na perspectiva holística) e o diálogo ativo com as políticas públicas que abordam o fenômeno social do envelhecimento populacional. Nesse debate, onde se julga relevante a incorporação do diálogo institucional dos sistemas de saúde e de assistência social, podem ser notadas complexas e dinâmicas características do enveIhecimento humano. Portanto, a possibilidade do avanço assistencial, 
na visão intersetorial, requisita da adopção de comportamentos que vão além do simples fato assistencial generalista. Inclui, no que lhe diz respeito, a compreensão ampliada do conceito de saúde, tecendo significados longínquos do modelo médico-hegemônico e o respeito aos direitos sociais outorgados ao segmento populacional envelhecido, como espaço para validar a mudança desse paradigma. Esses direitos, pela sua vez, referem a promoção da dignidade humana e a adoção de práticas assistenciais qualificadas.

Com a aprovação da Portaria N².528, em 19 de outubro de 2006, que promulgou a Política Nacional de Saúde da Pessoa Idosa (PNSI), surgiu à necessidade de redirecionar as medidas coletivas e individuais de saúde para os idosos. A PNSI reconhece que a "heterogeneidade dos idosos, seja em termos etários, de local de moradia ou socioeconômicos, acarreta demandas diferenciadas, o que tem rebatimento na formulação de políticas públicas para o segmento" (BRASIL, 2006). Nesse sentido, a PNSI estabelece como diretrizes operacionais a atenção integral, integrada à saúde da pessoa idosa e, em especial menção, o estímulo às ações intersetoriais, visando à integralidade da atenção (BRASIL, 2006).

Como potencialidade conceitual, a PIS rumada ao combate das DSS na velhice se vale não unicamente das ciências geriátrica e gerontológica para o alcance de seus objetivos. Convém-lhe, ademais, produzir ocasiões competentes nas diversas áreas do conhecimento, logo, de atuação dos profissionais incumbidos pela assistência ao idoso, em todos os domínios como ser humano. Para atingir mais precisamente tal fundamento, a PIS depende da existência de uma rede de suporte social, em junção ao apoio familiar no cuidado do idoso. Tais fatores são considerados como aspectos positivos para o estabelecimento e fortalecimento da atenção integral à saúde do idoso e podem, consequentemente, ser grandes aliados para a detecção e combate das DSS na velhice. Desse modo, a PIS responde pela função do cuidado longitudinal, na medida em que reconhece que alguns entraves assistenciais só podem ser resolvidos a médio e/ou longo prazo. 
Exemplo sucedido de PIS para o combate às DSS na velhice é o caso do “Disque Idoso", no município de Sobral, Ceará. O Disque Idoso se mostra como uma ferramenta inovadora por ter suas ações voltadas para a problemática da violência ao idoso, nas suas mais diversas manifestações, incorporando a intersetorialidade entre saúde, assistência social e a justiça legal, no acompanhamento domiciliar dos casos de violência contra o idoso (FREITAS; TEÓFILO, 2010). Adicionalmente, o programa potencializou a atenção domiciliar ao idoso com dificuldades físicas e/ou cognitivas.

Considerando aspectos jurídico-sanitários, cumpre frisar que o Conselho Nacional dos Direitos da Pessoa Idosa (CNDI) "visa favorecer a articulação e compartilhamento de atribuições entre diferentes setores, visando à implementação, densidade e abrangência das políticas para os idosos" (SOUZA; MACHADO, 2018, p. 3190). Portanto, “o CNDI representa uma estrutura inovadora de governança, que procura promover a articulação intersetorial entre órgãos públicos e ampliar a participação da sociedade civil nas políticas para os idosos" (SOUZA; MACHADO, 2018, p. 3198). O CNDI está estruturado por meio de comissões permanentes, que abordam diferentes setores que, de forma intersetorial, visam promover a qualidade de vida do segmento populacional envelhecido. No Quadro 02 são apresentadas as principais atribuições dessas comissões, segundo exposto por Souza e Machado (2018).

Quadro 02 - Atribuições das comissões do Conselho Nacional dos Direitos da Pessoa Idosa.

\begin{tabular}{|l|l|}
\hline $\begin{array}{l}\text { COMISSÕES } \\
\text { PERMANENTES }\end{array}$ & PRINCIPAIS ATRIBUIÇÕES \\
\hline Comissão de & $\begin{array}{l}\text { I- Acompanhar e avaliar a Política Nacional do Idoso; } \\
\text { II- assessorar, acompanhar e avaliar o plano estratégico } \\
\text { nacional de implementação das deliberações da Conferência } \\
\text { Nacional dos Direitos da Pessoa Idosa; III- criar mecanismos } \\
\text { e estratégias para assessorar e monitorar a formulação e } \\
\text { operacionalização dos planos estratégicos Estaduais, Distrital } \\
\text { e Municipais, decorrentes das respectivas conferências; entre } \\
\text { outras. }\end{array}$ \\
\hline
\end{tabular}




\begin{tabular}{|c|c|}
\hline $\begin{array}{l}\text { Comissão de } \\
\text { Orçamento e } \\
\text { Finanças }\end{array}$ & $\begin{array}{l}\text { I- Apreciar e acompanhar as diretrizes, propostas e execução } \\
\text { orçamentárias pertinentes ao segmento idoso, elaboradas } \\
\text { pelos Ministérios; II- Assessorar na formulação da proposta } \\
\text { orçamentária dos Planos Estratégicos das unidades federativas } \\
\text { e a execução financeira; III - identificar as necessidades da } \\
\text { Presidência e das demais Comissões no que diz respeito à } \\
\text { gestão administrativa e financeira do CNDI; IV- solicitar que a } \\
\text { Secretaria de Direitos Humanos informe os recursos previstos } \\
\text { para a gestão e funcionamento do CNDI, entre outras. }\end{array}$ \\
\hline $\begin{array}{l}\text { Comissão de } \\
\text { Normas }\end{array}$ & $\begin{array}{l}\text { I- Acompanhar, analisar, propor sobre a constitucionalidade } \\
\text { das matérias que lhe forem submetidas; II- propor alteração } \\
\text { no regimento interno do CNDI; III- propor a realização de } \\
\text { estudos, debates e pesquisas sobre a aplicação e os resultados } \\
\text { estratégicos alcançados pelos programas e projetos de } \\
\text { atendimento ao idoso. }\end{array}$ \\
\hline $\begin{array}{l}\text { Comissão de } \\
\text { Articulação com } \\
\text { Conselhos e } \\
\text { Comunicação Social }\end{array}$ & $\begin{array}{l}\text { I- Organizar coletânea de instrumentos legais que versem sobre } \\
\text { a PNI; II - organizar Resoluções do CNDI, resgatando a memória } \\
\text { histórica; III - divulgar as atividades do CNDI e da PNI; IV - } \\
\text { colaborar na divulgação das ações realizadas pelas entidades } \\
\text { civis representativas da pessoa idosa em âmbito nacional; V - } \\
\text { recomendar às Comissões Permanentes que seja dada ênfase } \\
\text { especial ao trabalho integrado governo e sociedade, etc. }\end{array}$ \\
\hline $\begin{array}{l}\text { Comissão de Gestão } \\
\text { do Fundo Nacional } \\
\text { do Idoso }\end{array}$ & $\begin{array}{l}\text { I- Elaborar anualmente os planos de trabalho e de aplicação } \\
\text { dos recursos do Fundo; II - definir os procedimentos e critérios } \\
\text { a serem contemplados nos Editais para a aprovação de } \\
\text { projetos a serem financiados com recursos do Fundo; III - } \\
\text { demandar aos responsáveis as informações necessárias ao } \\
\text { acompanhamento e avaliação das atividades apoiadas pelo } \\
\text { Fundo; IV - desenvolver atividades relacionadas à ampliação } \\
\text { da captação de recursos para o Fundo; V- avaliar e aprovar os } \\
\text { pedidos de registro das instituições e inscrição dos programas } \\
\text { junto ao CNDI, entre outras. }\end{array}$ \\
\hline
\end{tabular}

Fonte: Souza e Machado (2018, p. 3192).

Não obstante exista um marco jurídico-sanitário que releva a obrigação estatal de disponibilizar recursos e ambientes sustentáveis, no intuito a promover o desenvolvimento integral na última fase da vida humana, ainda é possível observar que a maioria das políticas são realizadas separadamente, não permitindo o diálogo ativo entre tais. A esse respeito, Oliveira; Ramos; Panhoca; Alves (2014, p. 92) comentam que, "no Brasil, a questão da intersetorialidade vem sendo bastante discutida nos últimos anos, contudo, ainda não existe um consenso que permita obter uma definição clara do próprio conceito". Na visão 
dos autores, a intersetorialidade "não seria uma estratégia de gestão das políticas públicas, e sim um processo político". O sentido no qual os autores orientam sua discussão permite asseverar que "as velhas políticas setoriais necessitam de novos tipos, conteúdos, ações e programas, que conformem áreas de interseção pertencentes a diversos tipos de políticas" (OLIVEIRA et al., 2014, p. 95).

A compreensão polissêmica da intersetorialidade também é discutida por Oliveira; Mattioli; Barcelos; Horta; Lacerda (2017, p. 186), ao afırmarem que o termo é de difícil definição e "a maioria das tentativas de qualificá-lo conceitualmente aponta para a ideia de superação da desintegração dos diferentes setores que compõem um dado campo de conhecimento e ação". Apesar disso, sua aplicabilidade representa importantes avanços para o fortalecimento das redes de atenção ao idoso e, com igual grau de incumbência, para o combate às DSS na velhice, posto que:

A organização do trabalho em rede amplia as possibilidades de ação, pois facilita a articulação entre as políticas setoriais e organizações, objetivando prevenir situações de risco social. Assim, o fluxo de informações contribui para o processo de mudança e facilita a intercomunicação entre os membros que compõem a rede de serviços, tornando as ações mais eficazes (OLIVEIRA et al., 2017, p. 185).

Embora pensada para ser uma ferramenta contra hegemônica, no que diz respeito à abordagem integral do envelhecimento humano como fenômeno de alta complexidade, a intersetorialidade em saúde ainda enfrenta importantes desafios, principalmente no concernente à práxis. A adopção de novos mecanismos de atuação tem sido apontada na literatura interdisciplinar como entrave técnico para o correto desenvolvimento dos sistemas assistenciais (NASCIMENTO, 2010; STAEVIE, 2017). Isso é, novas posturas intervencionistas significam novos entendimentos sobre a realidade (contexto - ambiente de trabalho), logo, dita realidade requisita de habilidades e atitudes 
profissionais mais assertivas perante tais cenários, circunstância nomeada por Staevie (2017) de "territorialidade do saber disciplinar". Por isso, "a efetivação de ações intersetoriais precisa vencer os obstáculos políticos nas três esferas de governo e avançar na formulação de modelos tecnoassistenciais condizentes com a realidade" (BORYSOW; FURTADO, 2013, p. 46).

Dessa forma, a importância da adoção da PIS pelos profissionais alocados em todos os níveis de atenção à saúde do idoso se deve ao fato de que "enquanto persistirem os posicionamentos setorizados no cuidado público, continuaremos a observar a falácia em detrimento da materialidade do direito à saúde" (CAVALCANTE; CARVALHO; MEDEIROS, 2012, p. 632). À vista desses impasses assistenciais, cumpre encorajar ocorrências antagônicas, naqueles casos em que a apropriação das PIS prevaleça sobre a prática hegemônica da produção de atos em saúde, em setores extremados e bio-medicalizados.

Faz-se jus complementar que "as políticas públicas para a velhice precisam avançar nos demais pontos para garantir os direitos sociais a todos os idosos, atendendo, assim, à premissa da integralidade" (ROCHA; ROMAGNOLI, 2015, p. 640). Em seguida, "destaca-se a importância de se romper com a ideia de um modelo único para atendimento à população, que limita a assistência de acordo com as necessidades do sistema e não do usuário" (COELHO; DA MOTTA; CALDAS, 2018, p. 16).

Finalmente, a PIS constitui novas oportunidades para repensar e rearticular a assistência sociossanitária disponibilizada ao idoso, na medida em que promove o fortalecimento dos vínculos entre os diversos setores incumbidos pela atenção às suas premências sociossanitárias, numa compreensão holística. Dessa forma, a PIS estende braços à integralidade das ações desempenhadas no SUS, pois "a intersetorialidade contribui para a transformação do conhecimento fragmentado, para criar uma estratégia de troca de saberes e práticas para uma ação coordenada que vise a um objetivo comum" (FAUSTINO, 2016, p. 96). 


\section{Considerações finais}

As observações trazidas nesse trabalho constataram posicionamentos já vislumbrados na literatura gerontológica. Em primeiro lugar, viu-se que a intersetorialidade configura prática inovadora no âmbito do SUS, abrangendo todas as esferas do cuidado (prevenção, promoção, reabilitação e recuperação), possuindo interpretações divergentes que, na maioria dos casos, se determinam pelo contexto no qual se pretende gerir, na pretensão maior de promover os direitos fundamentais outorgados à pessoa idosa. Em segundo lugar, o trabalho constatou que a PIS configura metodologia oportuna para combater as DSS na velhice, justamente porque o aspecto almejado, em quaisquer intervenções, é a promoção do princípio da integralidade na atenção ao idoso, como bem estipulado na PNSI.

Por ter-se tratado de uma revisão da literatura, o estudo apresentou como limitação o número reduzido de artigos $(n=10)$ que responderam ao objetivo traçado. Contudo, ressalta-se que o estudo não pretendeu esgotar a temática, mas levantar debate em relação à importância da PIS como ferramenta para o combate das DSS na velhice. Uma segunda limitação diz respeito ao campo de atuação dos estudos contemplados, já que somente foram contemplados trabalhos desenvolvidos no contexto do SUS, dificultando, dessa forma, a comparação com outras realidades dessemelhantes, quer sistemas públicos de saúde estrangeiros, quer setor privado da atenção à saúde.

Futuros estudos que visem descrever, através de diversas metodologias, a importância da inserção da PIS na assistência ao idoso se fazem necessários, pois se reconhece que as necessidades desse segmento populacional são heterogêneas e expressas por meio de constantes mudanças, em variados graus de complexidade. Entender a aplicabilidade das PIS para o fortalecimento das redes de atenção ao idoso possibilitaria, por sua vez, fortalecer os princípios doutrinários do SUS, que retomam à integralidade, universalidade e equidade dos serviços e programas oferecidos à população. 


\section{Referências}

ANTUNES, José Leopoldo Ferreira et al. Desigualdades sociais na autoavaliação de saúde dos idosos da cidade de São Paulo. Revista Brasileira de Epidemiologia, v. 21, n. Suppl 02, e180010, 2018. Disponível em: https://doi. org/10.1590/1980-549720180010.supl.2 Acesso em: 20 de out. 2020.

BORYSOW, Igor da Costa; FURTADO, Juarez Pereira. Acesso e intersetorialidade: o acompanhamento de pessoas em situação de rua com transtorno mental grave. Physis, Rio de Janeiro, v. 23, n.1, p.33-50, 2013. Disponível em: https:// doi.org/10.1590/S0103-73312013000100003. Acesso em: 20 de out. 2020.

BENTO, António. Como fazer uma revisão da literatura: Considerações teóricas e práticas. Revista JA (Associação Académica da Universidade da Madeira), vol. 7, no. 65, p. 42-44, 2012. Disponivel em: http://www3.uma.pt/ bento/Repositorio/Revisaodaliteratura.pdf. Acesso em: 20 de out. 2020.

BRASIL. Ministério da Saúde. Portaria n 2.528 de 19 de outubro de 2006. Aprova a Política Nacional de Saúde da pessoa Idosa. Disponível em https:// bvsms.saude.gov.br/bvs/saudelegis/gm/2006/prt2528_19_10_2006.html. Acesso em: 20 de out. 2020.

CACHIONI, Meire; DELFINO, Lais Lopes; YASSUDA, Mônica Sanches et al. Bem-estar subjetivo e psicológico de idosos participantes de uma Universidade Aberta à Terceira Idade. Rev. Bras. Geriatr. Gerontol., Rio de Janeiro; 20(3): 340-352, 2017. Disponível em: https://doi.org/10.1590/198122562017020.160179. Acesso em: 20 de out. 2020.

CAVALCANTE, Patrícia; CARVALHO, Rafael Nicolau; MEDEIROS, Katiusca Torres. Intersetorialidade, políticas sociais e velhice no Brasil: entre a falácia e a efetivação do direito social. Polêm!ca, v.11, n.4, p.628 a 634, 2012. Disponível em: https://doi.org/10.12957/polemica.2012.4330. Acesso em: 20 de out. 2020.

COELHO, Lívia Pereira; DA MOTTA, Luciana Branco; CALDAS, Célia Pereira. Rede de atenção ao idoso: fatores facilitadores e barreiras para implementação. Physis: Revista de Saúde Coletiva, Rio de Janeiro, v. 28(4), e280404, 2018. Disponivel em: https://doi.org/10.1590/s0103-73312018280404. Acesso em: 20 de out. 2020.

FAUSTINO, Taine Queithe da Silva. Intersetorialidade: tendência contemporânea na organização de políticas públicas - a experiência do Programa Maior Cuidado. Revista Ágora: Políticas Públicas, Comunicação e Governança informacional, v.1, n.1, p.78-103, 2016. Disponível em: https://periodicos.ufmg. br/index.php/revistaagora/article/view/2620. Acesso em: 20 de out. 2020. 
FREITAS, Cibelly Aliny Siqueira Lima; TEOFILO, Tiago José Silveira. Avaliação construtivista, sob uma abordagem integradora e intersetorial, das ações do Projeto Disque Idoso em Sobral (CE, Brasil). Ciência \& Saúde Coletiva, Rio de Janeiro, v.15, n.6, p.2825-2833, 2010. Disponivel em: https://doi.org/10.1590/ S1413-81232010000600020. Acesso em: 20 de out. 2020.

JUNQUEIRA, Luciano A. Prates. Desentrlização, intersetorialidade e rede na gestão da cidade. Organizações \& Sociedade, Salvador, v.11, n.spe, p.129-139, 2004. Disponível em: https://doi.org/10.1590/1984-9110009. Acesso em: 20 de out. 2020.

LIMA-COSTA, Maria Fernanda et al. Desigualdade social e saúde entre idosos brasileiros: um estudo baseado na pesquisa nacional por amostra de domicílios. Cadernos de Saúde Pública; 19(3):745-757, 2003. Disponível em: https:// doi.org/10.1590/S0102-311X2003000300007. Acesso em: 20 de out. 2020.

MANGUEIRA, Thayanne Nathanne Guarita. Intersetorialidade em saúde: algumas considerações. Sociedade Latino-americana de Couching, 2016. Disponivel em: https://www.slacoaching.com.br/intersetorialidade-em-saude-algumas-consideracoes. Acesso em: 20 de out. 2020.

MATTA, Gustavo Corrêa. "Princípios e diretrizes do sistema único de saúde" In: MATTA, G. C. Políticas de saúde: organização e operacionalização do sistema único de saúde. Rio de Janeiro: EPSJV/Fiocruz; 2007. p.61-80. Acesso em: 20 de out. 2020.

MEDEIROS, Flavia Cavalcante Nicolis. A intervenção do serviço social direcionada aos idosos: particularidades e desafios. O social em questão; 48(1):363-84. Disponivel em: http://osocialemquestao.ser.puc-rio.br/cgi/ cgilua.exe/sys/start.htm?infoid=773\&sid=63. Acesso em: 20 de out. 2020.

MINAYO, Maria Cecília de Souza; HARTZ, Zulmira Maria de Araújo; BUSS, Paulo Marchiori. Qualidade de vida e saúde: um debate necessário. Ciência \& Saúde Coletiva, vol. 5; 7-18, 2005. Disponível em: https://doi.org/10.1590/ S1413-81232000000100002. Acesso em: 20 de out. 2020.

MOTTA, Luciana Branco da; AGUIAR, Adriana Cavalcanti de; CALDAS, Célia Pereira. Estratégia Saúde da Família e a atenção ao idoso: experiências em três municípios brasileiros. Cadernos de Saúde Pública, Rio de Janeiro, v.27 n.4, p.779-786, 2011. Disponível em: https://doi.org/10.1590/S0102311X2011000400017. Acesso em: 20 de out. 2020.

MOTTA, Luciana Branco da; AGUIAR, Adriana Cavalcanti de. Novas competências profissionais em saúde e o envelhecimento populacional brasileiro: 
integralidade, interdisciplinaridade e intersetorialidade. Ciência \& Saúde Coletiva, Rio de Janeiro, v.12, n.2, p.363-372, 2007. Disponível em: https://doi. org/10.1590/S1413-81232007000200012. Acesso em: 20 de out. 2020.

NASCIMENTO, Sueli. Reflexões sobre a intersetorialidade entre as políticas públicas. Serviço Social e Sociedade, São Paulo, n. 101, p. 95-120, 2010. Acesso em: 20 de out. 2020.

NORONHA, Kenya Valéria Micaela de Souza; ANDRADE, Mônica Viegas. Desigualdades sociais em saúde e na utilização dos serviços de saúde entre os idosos na América Latina. Revista Panamericana de Salud Pública, vol. 17, p. 410-418, 2005. Disponível em: https://scielosp.org/pdf/rpsp/v17n5-6/26278. pdf. Acesso em: 20 de out. 2020.

OLIVEIRA, Antonio Deusivam; RAMOS, Oswaldo Alcanfor; PANHOCA, Ivone; ALVES, Vera Lúcia dos Santos. A intersetorialidade nas políticas públicas para o envelhecimento no Brasil. Revista Kairós Gerontologia, 17(2), pp.91-103, 2014. Disponivel em: https://doi.org/10.23925/2176-901X.2014v17i2p91-103. Acesso em: 20 de out. 2020.

OLIVEIRA, Tatiana Resende Prado Rangel; MATTIOLI, Cristiane Delesporte Pereira; BARCELOS, Bárbara Jacome; HORTA, Nátalia de Cássia; LACERDA, Tatiana Texeira Barral. Promoção da saúde e intersetorialidade na rede de atenção ao idoso. Geriatrics Gerontology \& Aging; 11(4):182-188, 2017. Disponível em: https://cdn.publisher.gn1.link/ggaging.com/pdf/CG_1700006_PT_ AOP.pdf. Acesso em: 20 de out. 2020.

ORGANIZAÇÃO DAS NAÇÕES UNIDAS - ONU. Transformando nosso mundo: a Agenda 2030 para o Desenvolvimento Sustentável, 2015. Acesso em: 20 de out. 2020.

PEREIRA, Potyara Amazoneida Pereira. Envelhecimento, direitos e garantias sociais. Geriatrics, Gerontology and Aging, v. 9, p.122-125, 2015. Disponível em: https://cdn.publisher.gn1.link/ggaging.com/pdf/v9n3a08.pdf. Acesso em: 20 de out. 2020.

PÉREZ-HERNÁNDEZ, Bibiana et al. Desigualdades sociales en los factores de riesgo cardiovascular de los adultos mayores de España: estudio ENRICA-Senior. Revista Española de Cardiologia, 70(3):145-154, 2017. Disponível em: https://www.revespcardiol.org/es-desigualdades-sociales-factores-deriesgo-cardiovascular-articulo-S0300893216302536. Acesso em: 20 de out. 2020. 
ROCHA, Ana Paula Lopes; ROMACNOLI, Roberta Carvalho. Cuidado com a velhice: interdisciplinaridade e intersetorialidade. Psicologia Revista (Belo Horizonte); v.21, n.3, p. 638-640, 2015. Disponivel em: http://pepsic.bvsalud. org/scielo.php?script=sci_arttext\&pid=S1677-11682015000300014. Acesso em: 20 de out. 2020.

STAEVIE, Pedro Marcelo. Interdisciplinaridade: contribuições para se pensar a Amazônia. Revista Latino-Americana de Estudos Avançados, v.2, n.1, 2017. Disponível em: https://revistas.unila.edu.br/relea/article/view/766. Acesso em: 20 de out. 2020.

SCHUMACHER, Aluisio Almeida; PUTTINI, Rodolfo Franco; NOJIMOTO, Toshio. Vulnerabilidade, reconhecimento e saúde da pessoa idosa: autonomia intersubjetiva e justiça social. Saúde em debate, Rio de Janeiro; v. 37, n. 97, p. 281-293, 2013. Disponivel em: https://www.scielo.br/scielo.php?pi$d=S 0103-11042013000200010 \& s c r i p t=s c i \_a b s t r a c t \& t \mid n g=p t$. Acesso em: 20 de out. 2020.

SOUZA, Michele Souza e; MACHADO, Cristiani Vieira. Governança, intersetorialidade e participação social na política pública: o Conselho Nacional dos Direitos da Pessoa Idosa. Ciência \& Saúde Coletiva, Rio de Janeiro, v.23, n.10, p.3189-3200, 2018. Disponivel em: http://www.cienciaesaudecoletiva.com.br/artigos/governanca-intersetorialidade-e-participacao-social-na-politica-publica-o-conselho-nacional-dos-direitos-da-pessoa-idosa/16821?id=16821. Acesso em: 20 de out. 2020.

VEIGA, Laura da; BRONZO, Carla. Estratégias intersetoriais de gestão municipal de serviços de proteção social: a experiência de Belo Horizonte. Revista de Administração Pública, Rio de Janeiro, v. 48, n. 3, p. 595-620, 2014. Disponível em: http://dx.doi.org/10.1590/0034-76121453. Acesso em: 20 de out. 2020.

\section{Nota}

1 Bacharel em Saúde Coletiva - Universidade Federal da Integração Latino-americana (UNILA). Mestrando no Programa de Pós-graduação Stricto Senso em Gerontologia - Universidad Europea del Atlántico (UNEATLANTICO). Sanitarista Residente no Programa Lato Senso em Residência Multiprofissional em Saúde da Família - (UNILA). Orcid nº 0000-0003-2304-3241. E-mail: stevengumu@gmail.com. 


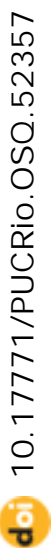

